\title{
An Alternate Formula in terms of Pi to find the Area of a Triangle and a Test to decide the True Pi value (Atomic Energy Commission Method*)
}

\author{
R.D. Sarva Jagannadha Reddy
}

Abstract: Circle, square and triangle are basic geometrical constructions. $\pi$ constant is associated with the circle. In this paper, circle-triangle interlationship chooses the real value of $\pi$ and calculating the area of the triangle involving $\pi$ of the inscribed circle. The alternate formula to find the area of the triangle is $\left(\frac{3 \sqrt{3} \pi}{14-\sqrt{2}}\right) \mathrm{d}^{2}$. This formula has a geometrical backing.

Keywords: Altitude, base, circle, diameter, perimeter, triangle

\section{Introduction}

The official $\pi$ value is $3.14159265358 \ldots$ It is an approximation, inspite of having trillions of its decimals. A new value to $\pi$ was discovered in March 1998. The value is $\frac{14-\sqrt{2}}{4}=3.14644660942 \ldots$ Both the $\pi$ values have their own supporting arguments. Triangle is another geometrical entity. Its area is calculated using the formula $1 / 2 a b$, where $a=$ altitude and $b=$ base. In this paper, a different formula has been derived to find out the area of the equilateral triangle based on the $\pi$ of its inscribed circle. The formula $1 / 2$ ab gives the area of the triangle. No other formula is necessary for the area of triangle. The main purpose of derivation of new area formula of triangle is, to test the correctness of $\pi$ value involved in the new formula.

One advantage in using the new formula for area of the triangle is, the resulting value tally's exactly with the value of $1 / 2 \mathrm{ab}$ only, when the chosen $\pi$ value is correct one. If the wrong/ approximate $\pi$ value is involved in the new formula, it does not give exact value of the triangle. In other words, out of the two numbers $3.14159265358 \ldots$ and $\frac{14-\sqrt{2}}{4}=3.14644660942 \ldots$ only one number, gives the exact area of the triangle. The number which fails in giving exact value to the area of the triangle is decided as the wrong $\pi$ value.

\section{Procedure}

Draw a circle with centre ' $O$ ' and radius $\frac{\mathrm{d}}{2}$. Draw three equidistant tangents on the circle. The tangents intersect at $\mathrm{A}, \mathrm{B}$ and $\mathrm{C}$, creating an equilateral triangle $\mathrm{ABC}$. $\mathrm{DE}$ is the hypotenuse of DOE triangle or the chord of the circle.

\section{Calculations:}

Centre $=\mathrm{O}$

Radius $=\mathrm{OD}=\mathrm{OE}=\frac{\mathrm{d}}{2}$

Diameter $=\mathrm{DF}=\mathrm{d}$

Triangle $=\mathrm{ABC}$

Side $=\mathrm{AB}=\mathrm{BC}=\mathrm{AC}=\mathrm{a}=\sqrt{3} \mathrm{~d}$

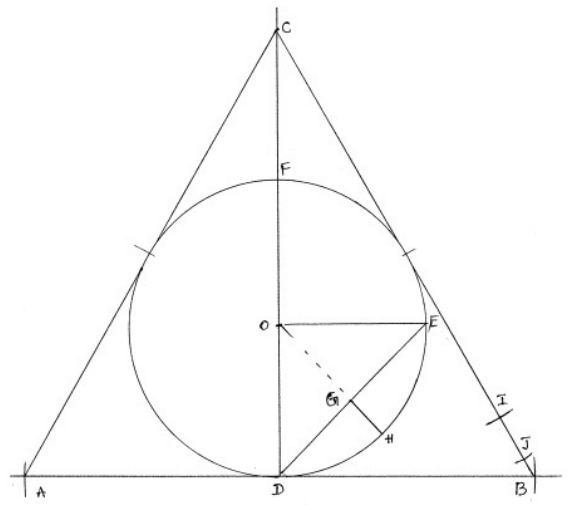

\footnotetext{
* This author was awarded Merit Scholarship by Atomic Energy Commission, Trombay, Bombay for his M.Sc., (Zoology) study in S.V. University College, Tirupati, Chittoor Dt. A.P.,India, during 1966-68. This author is highly indebted to the AEC and hence this paper is named in the AECs' Honour.
} 
Altitude $=\mathrm{DC}=\frac{3 \mathrm{~d}}{2}$

Radius $=\mathrm{OE}=\mathrm{OD}=\frac{\mathrm{d}}{2}$

Hypotenuse $=$ Chord $=\mathrm{DE}=\frac{\mathrm{d}}{2} \times \sqrt{2}=\frac{\sqrt{2} \mathrm{~d}}{2}$

Area of the triangle by Conventional formula

$\frac{1}{2} \mathrm{ab}=\frac{1}{2} \times \mathrm{DC} \times \mathrm{AB}=\frac{1}{2} \times \frac{3 \mathrm{~d}}{2} \times \sqrt{3} \mathrm{~d}=\left(\frac{3 \sqrt{3}}{4}\right) \mathrm{d}^{2}$

\section{New formula to find the area of $\mathrm{ABC}$ triangle}

Perimeter of the $\mathrm{ABC}$ triangle $3 \times \mathrm{AB}=3 \times \sqrt{3} \mathrm{~d}=3 \sqrt{3} \mathrm{~d}$

4 times of perimeter of the $\mathrm{ABC}$ triangle

14 times of diameter DF of circle -2 times of chord DE

$$
=\frac{4(3 \sqrt{3} d)}{14 d-2\left(\frac{\sqrt{2} d}{2}\right)}=\frac{12 \sqrt{3}}{14-\sqrt{2}}
$$

To find out the area of the $\mathrm{ABC}$ triangle, multiply the area of the circle with $\frac{12 \sqrt{3}}{14-\sqrt{2}}$

Area of the circle $=\frac{\pi \mathrm{d}^{2}}{4}$

Area of the $\mathrm{ABC}$ triangle $=$ Area of the circle $\mathrm{x} \frac{12 \sqrt{3}}{14-\sqrt{2}}$

$$
=\frac{\pi \mathrm{d}^{2}}{4} \times \frac{12 \sqrt{3}}{14-\sqrt{2}}=\left(\frac{3 \sqrt{3} \pi}{14-\sqrt{2}}\right) \mathrm{d}^{2} \quad \text { where } \mathrm{d}=\text { diameter of the inscribed circle }
$$

Thus, $\left(\frac{3 \sqrt{3} \pi}{14-\sqrt{2}}\right) \mathrm{d}^{2}$ is the new formula to find out the area of the superscribed triangle about a circle.

Where $\pi$, may be 3.14159265358 or $3.14644660942=\frac{14-\sqrt{2}}{4}$

Area of the $\mathrm{ABC}$ equilateral triangle besides from the $1 / 2$ ab formula is $=\left(\frac{\sqrt{3}}{4}\right) \mathrm{a}^{2}$

where $\mathrm{a}=\sqrt{3} \mathrm{~d}$

$$
=\frac{1}{2} \times \frac{3 \mathrm{~d}}{2} \times \sqrt{3} \mathrm{~d}=\left(\frac{3 \sqrt{3}}{4}\right) \mathrm{d}^{2}=\left(\frac{\sqrt{3}}{4}\right)(\sqrt{3} \mathrm{~d})^{2}=\left(\frac{3 \sqrt{3}}{4}\right) \mathrm{d}^{2}
$$

So, the value $\left(\frac{3 \sqrt{3}}{4}\right) \mathrm{d}^{2}$ as the area of the $\mathrm{ABC}$ triangle, should also be obtained, using the above new formula, derived in terms of $\pi$

$$
\left(\frac{3 \sqrt{3} \pi}{14-\sqrt{2}}\right) d^{2} \text { should be equal to }\left(\frac{3 \sqrt{3}}{4}\right) d^{2}
$$


The unknown one in the above is $\pi$. Let us write formula with two different $\pi$ values.

$$
\begin{aligned}
& \left.\begin{array}{l}
\left(\frac{3 \sqrt{3} \times 3.14159265358}{14-\sqrt{2}}\right) d^{2} \\
\text { OR } \\
\left(\frac{3 \sqrt{3} \times \frac{14-\sqrt{2}}{4}}{14-\sqrt{2}}\right) d^{2}
\end{array}\right\}=\left(\frac{3 \sqrt{3}}{4}\right) d^{2} \text { should be } \\
& \left(\frac{3 \sqrt{3} \times 3.14159265358}{14-\sqrt{2}}\right) \times 1 \times 1 \quad \text { where } \mathrm{d}=1 \\
& =1.29703410738 \text {, we have obtained this value } \\
& \text { instead of } \frac{3 \sqrt{3}}{4}=1.29903810567
\end{aligned}
$$

So, official $\pi$ value 3.14159265358 has failed to give $\frac{3 \sqrt{3}}{4}$ as the value of the area of ABC triangle. On the otherhand, new $\pi$ value $\frac{14-\sqrt{2}}{4}$ has given $\frac{3 \sqrt{3}}{4}$ as the area of $\mathrm{ABC}$ triangle. This shows, that the new $\pi$ value $\frac{14-\sqrt{2}}{4}$ is the real $\pi$ value.

Equating conventional formulas $1 / 2 \mathrm{ab}=\left(\frac{\sqrt{3}}{4}\right) \mathrm{a}^{2}$ to new formula $\left(\frac{3 \sqrt{3} \pi}{14-\sqrt{2}}\right) \mathrm{d}^{2}$ is itself a justification and a naked truth of latter's correctness.

\section{Conclusion}

$1 / 2 \mathrm{ab}$ is the formula to find out the area of a triangle. In this paper, a new formula $\left(\frac{3 \sqrt{3} \pi}{14-\sqrt{2}}\right) \mathrm{d}^{2}$ is derived. This formula by giving the exact area of $\mathrm{ABC}$ triangle shows, that circle and the equilateral triangle are clearly interrelated and are not very different as we have been believing. The benefit we derive by using this formula is, this formula chooses the real $\pi$ value, discarding other approximate values attributed to $\pi$. This method alone, for the first time in the history of mathematics, acts as a testing method of $\pi$ and boldly says Archiemedes' upper limit of $3 \frac{1}{7}$ or $\frac{22}{7}$ is a lower value compared to the real $\pi$ number.

\section{Post script}

As it is proved in this paper that the real $\pi$ value is $\frac{14-\sqrt{2}}{4}$ based on the area of the triangle $\mathrm{ABC}$, it has made possible to demarcate the length of the circumference of the inscribed circle in the straight-lined perimeter of the ABC triangle. How?

Let us know first the length of the circumference of the inscribed circle with the known $\pi$ value $\frac{14-\sqrt{2}}{4}$

Diameter $=\mathrm{d}$

Circumference $=\pi \mathrm{d}$ 
$\pi=\frac{14-\sqrt{2}}{4}$

When the diameter is equal to 1 , the circumference $=\pi$ value

Let us search for the line-segments equal to $\frac{14-\sqrt{2}}{4}$.

Diameter $=\mathrm{DF}=\mathrm{d}$

Altitude of $\mathrm{ABC}$ triangle $=\mathrm{DC}=\frac{3 \mathrm{~d}}{2}$

Radius $=\mathrm{OH}=\frac{\mathrm{d}}{2}$

$\mathrm{DE}=$ hypotenuse $=$ Chord $=\frac{\sqrt{2} \mathrm{~d}}{2}$

$\mathrm{G}$ is the mid point of $\mathrm{DE}$

So, $\mathrm{DG}=\mathrm{GE}=\mathrm{OG}=\frac{\sqrt{2} \mathrm{~d}}{4}$

$\mathrm{OG}=\frac{\sqrt{2} \mathrm{~d}}{4}$

$\mathrm{GH}=$ Radius $-\mathrm{OG}=\frac{\mathrm{d}}{2}-\frac{\sqrt{2} \mathrm{~d}}{4}=\left(\frac{2-\sqrt{2}}{4}\right) \mathrm{d}$

$\mathrm{CI}=\mathrm{DC}=\frac{3 \mathrm{~d}}{2}$

$\mathrm{IJ}=\mathrm{GH}=\left(\frac{2-\sqrt{2}}{4}\right) \mathrm{d}$

Circumference of the circle $\pi \mathrm{d}=\left(\frac{14-\sqrt{2}}{4}\right) \mathrm{d}$, So, the demarcated length DCJ in the perimeter of the ABC triangle is equal to the circumference of the inscribed circle.

$\mathrm{DC}+\mathrm{CI}+\mathrm{IJ}=\frac{3 \mathrm{~d}}{2}+\frac{3 \mathrm{~d}}{2}+\left(\frac{2-\sqrt{2}}{4}\right) \mathrm{d}=\left(\frac{14-\sqrt{2}}{4}\right) \mathrm{d}$

Thus the straight lined length equal to length of the curvature of the circumference of the inscribed circle is called rectification of circumference of a circle. It was done never before. People tried earlier in the perimeter of the square but never in the perimeter of the triangle.

\section{References}

[1]. Lennart Berggren, Jonathan Borwein, Peter Borwein (1997), Pi: A source Book, $2^{\text {nd }}$ edition, Springer-Verlag Ney York Berlin Heidelberg SPIN 10746250.

[2]. Alfred S. Posamentier \& Ingmar Lehmann (2004), $\pi$, A Biography of the World's Most Mysterious Number, Prometheus Books, New York 14228-2197.

[3]. RD Sarva Jagannada Reddy (2014), New Method of Computing Pi value (Siva Method). IOSR Journal of Mathematics, e-ISSN 2278-3008, p-ISSN: 2319-7676. Volume 10, Issue 1 Ver. IV. (Feb. 2014), PP 48-49.

[4]. RD Sarva Jagannada Reddy (2014), Jesus Method to Compute the Circumference of A Circle and Exact Pi Value. IOSR Journal of Mathematics, e-ISSN: 2278-3008, p-ISSN: 2319-7676. Volume 10, Issue 1 Ver. I. (Jan. 2014), PP 58-59.

[5]. RD Sarva Jagannada Reddy (2014), Supporting Evidences To the Exact Pi Value from the Works Of Hippocrates Of Chios, Alfred S. Posamentier And Ingmar Lehmann. IOSR Journal of Mathematics, e-ISSN: 2278-3008, p-ISSN:2319-7676. Volume 10, Issue 2 Ver. II (Mar-Apr. 2014), PP 09-12

[6]. RD Sarva Jagannada Reddy (2014), New Pi Value: Its Derivation and Demarcation of an Area of Circle Equal to Pi/4 in A Square. International Journal of Mathematics and Statistics Invention, E-ISSN: 2321 - 4767 P-ISSN: 2321 - 4759. Volume 2 Issue 5, May. 2014, PP-33-38.

[7]. RD Sarva Jagannada Reddy (2014), Pythagorean way of Proof for the segmental areas of one square with that of rectangles of adjoining square. IOSR Journal of Mathematics, e-ISSN: 2278-3008, p-ISSN:2319-7676. Volume 10, Issue 3 Ver. III (May-Jun. 2014), PP 17-20. 
[8]. RD Sarva Jagannada Reddy (2014), Hippocratean Squaring Of Lunes, Semicircle and Circle. IOSR Journal of Mathematics, eISSN: 2278-3008, p-ISSN:2319-7676. Volume 10, Issue 3 Ver. II (May-Jun. 2014), PP 39-46

[9]. RD Sarva Jagannada Reddy (2014), Durga Method of Squaring A Circle. IOSR Journal of Mathematics, e-ISSN: 2278-3008, pISSN:2319-7676. Volume 10, Issue 1 Ver. IV. (Feb. 2014), PP 14-15

[10]. RD Sarva Jagannada Reddy (2014), The unsuitability of the application of Pythagorean Theorem of Exhaustion Method, in finding the actual length of the circumference of the circle and Pi. International Journal of Engineering Inventions. e-ISSN: 2278-7461, pISSN: 2319-6491, Volume 3, Issue 11 (June 2014) PP: 29-35.

[11]. RD Sarva Jagannadha Reddy (2014), Pi of the Circle, at www.rsjreddy.webnode.com

[12]. R.D. Sarva Jagannadha Reddy (2014). Pi treatment for the constituent rectangles of the superscribed square in the study of exact area of the inscribed circle and its value of Pi (SV University Method*). IOSR Journal of Mathematics (IOSR -JM), e-ISSN: 22785728, p-ISSN:2319-765X. Volume 10, Issue 4 Ver. I (Jul-Aug. 2014), PP 44-48 